\title{
FAKTOR-FAKTOR YANG MEMPENGARUHI PERKEMBANGAN DESA SIAGA DI WILAYAH KERJA PUSKESMAS KERUMUTAN PANGKALAN KERINCI TAHUN 2013
}

\author{
Ardenny $^{1}$, Delvira, $\mathbf{W}^{2}$ \\ Poltekkes Kemenkes Pekanbaru; J1.Melur No.103 Sukajadi \\ Email: ardenny_2010@yahoo.co.id
}

\begin{abstract}
Abstrak
Pembangunan kesehatan menuju Indonesia Sehat 2020 bertujuan untuk meningkatkan kesadaran, kemauan dan kemampuan hidup sehat bagi setiap orang agar terwujud derajat kesehatan masyarakat setinggi-tingginya melalui terciptanya masyarakat, bangsa dan negara Indonesia yang ditandai dengan penduduknya yang hidup dengan perilaku dalam lingkungan yang sehat memiliki kemampuan untuk menjangkau pelayanan kesehatan yang bermutu secara adil dan merata. Hal ini didasari dari paradigma sehat antara lain terjadinya pergeseran dari pelayanan medis kepemulihan kesehatan sehingga setiap upaya penanggulangan masalah kesehatan lebih menonjolkan aspek peningkatan (promotif), pencegahan (preventif) dibanding pengobatan (kuratif). Langkah nyata untuk mewujudkan sasaran tersebut telah terbit SK/MENKES/No. 564/ 2006 tentang pedoman pelaksanaan desa siaga dengan mengambil kebijakan bahwa seluruh desa di Indonesia menjadi desa siaga pada akhir tahun 2008 (Depkes RI, 2007). Tujuan penelitian ini bertujuan untuk mengetahui faktor-faktor apa yang mempengaruhi perkembangan desa siaga di Wilayah kerja Puskesmas Kerumutan Pangkalan Kerinci. Jenis Penelitian ini bersifat deskriptif korelasi dengan rancangan chi square. Teknik pengambilan sampel dengan menggunakan stratified random sampling yaitu sebanyak 212 orang. Analisis data yang digunakan adalah univariat (central tendency) dan bivariate (uji chi square). Hasil penelitian menunjukkan bahwa secara statistik terdapat sebagian besar tidak tersedianya bidan di desa siaga yaitu sebanyak 115 orang $(54,2 \%)$, kader tidak aktif dalam kegiatan desa siaga yaitu sebanyak 113 orang $(53,3 \%)$, dan sarana prasarana tidak tersedia di desa siaga yaitu sebanyak 109 orang (51,4\%).Sedangkan hubungan antar variabel di dapatkan data bahwa terdapat hubungan yang signifikan antara faktor bidan $(p=0,001)$, kader $(p=0,001)$, dan sarana prasarana $(p=0,001)$ terhadap perkembangan desa siaga di wilayah kerja Puskesmas Kerumutan Pangkalan Kerinci. Disarankan pada responden masyarakat dapat meningkatkan kesadarannya dalam meningkatakan derajat kesehatan melalui pembinaan oleh bidan desa dan kader kesehatan yang sudah terlatih. Peran serta masyarakat dalam pengembangan desa siaga juga memberikan kontribusi dalam mewujudkan derajat kesehatan yang optimal.
\end{abstract}

Kata kunci : Bidan, desa siaga, kader, sarana prasarana

\section{Abstract}

Health development towards Healthy Indonesia 2020 aims to increase awareness, willingness and ability of healthy life for every person to manifest the health of society 
through the creation of the highest society, nation and state of Indonesia which is characterized by the behavior of the population living in a healthy environment has the ability to quality health services to reach a fair and equitable manner. The development of public health science has led us to a new paradigm, that paradigm has now become a healthy new orientation of development of health in the world, including in Indonesia, which is encapsulated in the vision of Healthy Indonesia 2020. This is based on the paradigm of healthy, among others, the shift from medical services so that health kepemulihan any efforts to control health problems further highlight the aspects of improvement (promotion), prevention (preventive) than treatment (curative). Concrete steps to achieve these goals has been published SK / Minister of Health / No . 564/2006 on guidelines for the implementation of idle village by taking a policy that all villages in Indonesia to alert the village at the end of 2008 (Depkes, 2007). The objective of this study aims to determine what factors influence the development of villages in the Region Puskesmas standby Kerumutan Pangkalan Kerinci. This research type is descriptive correlation with chi square design. Sampling technique using a stratified random sampling as many as 212 people. Analysis of the data used are univariate (central tendency) and bivariate (chi square test). The results showed that there are statistically most midwives unavailability idle as many as 115 people ( $54.2 \%$ ), cadres not active in standby villages as many as 113 people $(53.3 \%)$, and the infrastructure is not available in standby villages as many as 109 people ( $51.4 \%$ ). Meanwhile, the relationship between variables in the data get that there is a significant relationship between midwives factor $(p=0.001)$, cadre $(p=0.001)$, and infrastructure $(p=0.001)$ against developments in the standby village Puskesmas Kerumutan Pangkalan Kerinci. The respondents suggested that people can improve health status by increasing awareness through guidance by midwives and health workers who are already trained. Community participation in rural development idle also contributed in achieving optimal health status .

Keywords: Midwives, standby village cadres, infrastructur

\section{Pendahuluan}

Pembangunan kesehatan menuju Indonesia

Sehat 2020 bertujuan untuk meningkatkan kesadaran, kemauan dan kemampuan hidup sehat bagi setiap orang agar terwujud derajat kesehatan masyarakat setinggi-tingginya melalui terciptanya masyarakat, bangsa dan Negara Indonesia yang ditandai dengan penduduknya yang hidup dengan perilaku dalam lingkungan yang sehat memiliki kemampuan untuk menjangkau pelayanan kesehatan yang bermutu secara adil dan merata. Maka untuk keberhasilan pembangunan kesehatan perlu adanya strategi dalam pemberdayaan masyarakat dan daerah yaitu penyelenggaraan berbagai upaya kesehatan harus berangkat dari masalah dan potensi spesifik daerah. Oleh karena, dalam pembangunan kesehatan diperlukan adanya pendelegasian wewenang yang lebih besar kepada daerah untuk mengatur sistem pemerintahan dan rumah 
tangga sendiri (Depkes RI, 2009). Sesuai dengan Visi Indonesia Sehat 2020, programprogram pembangunan kesehatan diselenggarakan dalam upaya meningkatkan perilaku hidup sehat, mewujudkan lingkungan hidup yang sehat, dan pelayanan kesehatan yang bermutu, adil dan merata. Kesehatan adalah hak azazi manusia dan sekaligus investasi untuk keberhasilan pembangunan bangsa. Untuk itu diselenggarakan pembangunan kesehatan secara menyeluruh dan berkesinambungan, dengan tujuan guna meningkatkan kesadaran, kemauan, dan kemampuan hidup sehat bagi setiap orang dengan terwujudnya derajat kesehatan masyarakat yang setinggitingginya (Depkes RI, 2004). Perkembangan ilmu kesehatan masyarakat telah mengantar kita pada paradigma baru, sehingga kini paradigma sehat menjadi orientasi baru pembangunan kesehatan di dunia, termasuk di Indonesia yang dirumuskan dalam visi Indonesia Sehat 2020. Hal ini didasari dari paradigma sehat antara lain terjadinya pergeseran dari pelayanan medis kepemulihan kesehatan sehingga setiap upaya penanggulangan masalah kesehatan lebih menonjolkan aspek peningkatan (promotif), pencegahan (preventif) dibanding pengobatan (kuratif) (Depkes RI, 2003).

Langkah nyata untuk mewujudkan sasaran tersebut telah terbit SK/MENKES/ No. 564/ 2006 tentang pedoman pelaksanaan Desa Siaga (Siap Antar Jaga) dengan mengambil kebijakan bahwa seluruh desa di Indonesia menjadi Desa Siaga pada akhir tahun 2008 (Depkes RI, 2007). Kriteria desa siaga adalah apabila desa tersebut telah memiliki sekurang-kurangnya sebuah Pos Kesehatan Desa (Poskesdes). Poskesdes merupakan salah satu bentuk dari UKBM (Upaya Kesehatan Bersumber Daya Masyarakat) yang dibentuk di Desa Siaga dalam rangka mendekatkan pelayanan kesehatan dasar bagi masyarakat desa. Syarat berdirinya sebuah desa siaga minimal diisi oleh 1 (satu) bidan dengan didampingi 2 (dua) kader (Depkes RI, 2009). Adanya ketersediaan desa siaga penyebarluasan informasi ke masyarakat semakin mudah dan masyarakat dapat ikut untuk memberikan pengabdian di bidang kesehatan, melakukan upaya advokasi dan ikut mengkritis terhadap pelaksanaan upaya kesehatan. Hal ini dapat meningkatkan derajat kesehatan masyarakat. Adapun indikator derajat kesehatan masyarakat yang sensitif meliputi angka kematian bayi, angka kematian balita, angka kematian ibu dan persentase gizi buruk pada balita dan angka harapan hidup (Depkes RI, 2009). Keberhasilan program desa siaga dapat dipengaruhi oleh beberapa faktor seperti faktor pengetahuan, sikap, tenaga kesehatan, sarana dan prasarana yang memudahkan masyarakat untuk memanfaatkan fasilitas yang ada (Depkes RI, 2009). Hasil penelitian yang dilakukan oleh Mutmainah (2010) di Desa Lawangaji Kabupaten Batang diperoleh 
data bahwa faktor dominan yang mempengaruhi keberhasilan desa siaga adalah faktor tenaga kesehatan dan sarana prasarana yang tersedia. Hasil penelitian lain yang dilakukan oleh Junardi (2011) di Desa Sidikalang Kabupaten Dairi, diperoleh data bahwa faktor yang mempengaruhi rendahnya pemanfaatan desa siaga adalah faktor keberadaan petugas kesehatan dan fasilitas penunjang seperti ambulans siaga yang dibutuhkan untuk layanan rujukan pada kasus emergensi.

Desa siaga yang berada di wilayah kerja Puskesmas Kerumutan berjumlah 10 desa yang tersebar di Kelurahan Kerumutan. Dari sepuluh desa siaga tersebut, belum semuanya terlaksana dengan baik, hanya enam desa yang berjalan sesuai dengan standar Kelurahan Siaga. Hal ini disebabkan oleh karena terbatas jumlah tenaga kesehatan yang siaga dalam memberikan pelayanan, fasilitas kesehatan seperti transportasi darat yang dibutuhkan untuk rujukan pada penyakit emergensi terutama pada kasus persalinan dan kegawatdaruratan. Kelurahan Siaga disini hanya berupa pelayanan saja dan belum sebahagian besar yang mempunyai gedung sendiri, ambulans desa, dan tokoh masyarakat yang aktif termasuk Kelurahan Siaga yang berada dalam wilayah kerja Puskesmas Kerumutan.

Jumlah tenaga kesehatan yang ideal pada setiap Desa Siaga adalah minimal 2 orang, sementara tenaga yang ada di empat desa siaga seperti Desa Lipai Bulan, Tanjung Air Hitam, Pangkalan Tampui, dan Mak Teduh hanya memiliki satu orang bidan. Sehingga hal ini memberi kemungkinan untuk tidak selalu berada di tempat ketika masyarakat membutuhkan sesuatu untuk mendapatkan pelayanan, oleh karena tidak ada tenaga pengganti disaat kesibukan yang dilakukan secara rutin oleh bidan desa siaga seperti mengikuti rapat-rapat penting di Puskesmas Induk, Loka Karya Mini, dan beberapa pelatihan teknis maupun non teknis yang terkadang memerlukan waktu yang lama. Hal ini membuat masyarakat setempat merasa terlantar, dan keluhan masalah kesehatan yang dirasakan semakin bertambah berat.

Perlu diketahui juga, bahwa pelakasanaan pelayanan kesehatan desa siaga terutama pada empat desa yang belum berkembang sebagaimana disebutkan di atas, juga belum memiliki kader yang membantu bidan dalam pelayanan desa siaga. Hal ini disebabkan oleh karena belum adanya tenaga yang mau berperan sebagai kader sukarela dalam menjalankan kemitraan dengan bidan desa siaga. Selain itu juga, tidak tersedianya transportasi seperti ambulans gawat darurat yang merupakan hambatan bagi Desa Siaga dalam melayani kesehatan di masyarakat setempat.

Berdasarkan latar belakang di atas penulis merasa tertarik untuk mengetahui faktorfaktor apa yang mempengaruhi perkembangan desa siaga di Wilayah kerja 
Puskesmas Kerumutan Pangkalan Kerinci

tahun 2013.

\section{Tujuan Penelitian}

Untuk mengetahui faktor-faktor yang mempengaruhi perkembangan di wilayah kerja Puskesmas Kerumutan Kabupaten Pelalawan tahun 2013.

\section{Metode Penelitian}

Penelitian ini bersifat deskriptif analitik dengan menggunakan desain cross-sectional study yaitu untuk mengetahui faktor-faktor yang mempengaruhi perkembangan di wilayah kerja Puskesmas Kerumutan Kabupaten Pelalawan. Data yang dikumpulkan secara serentak pada individuindividu dari suatu populasi pada saat yang bersamaan (point time approach).

\section{Hasil Penelititan}

Penelitian dilakukan di wilayah kerja Bidan

Puskesmas Kerumutan Kabupaten Pelalawan dilakukan mulai tanggal 02 s.d 14 Januari

2014. Pengumpulan data dilakukan oleh Keaktifan peneliti dengan menyebarkan lembar ${ }^{-T}$ Ak kuesioner kemudian dibagikan kepada 212 responden dan dijawab secara lengkap. Data yang diambil yaitu mengenai faktor-faktor yang mempengaruhi perkembangan $\mathrm{di}^{-}$

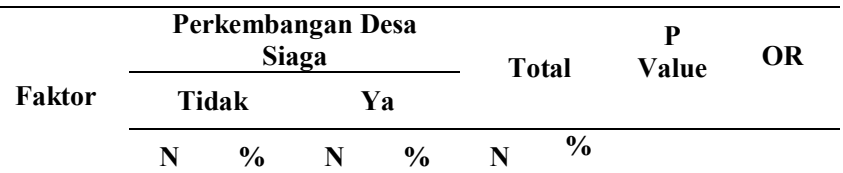
Tabel 5.1 Hasil Analisis Univariat Menurut Perkembangan desa siaga dan faktor yang mempengaruhi Tahun $2013(n=212)$

\begin{tabular}{clcc}
\hline No & \multicolumn{1}{c}{ Faktor } & f & \% \\
\hline 1. & Perkembangan desa siaga: & & \\
& a. Tidak berkembang & 112 & 52,8 \\
& b. Berkembang & 100 & 47,2 \\
\hline 2. & Ketersediaan bidan: & & \\
& a. Tidak tersedia & 115 & 52,4 \\
& b. Tersedia & 97 & 97 \\
\hline 3. & Keaktifan kader: & 113 & 53,3 \\
& a. Tidak aktif & 99 & 46,7 \\
\hline & b. Aktif & & \\
4. Ketersdiaan Sarana Prasana: & 109 & 51,4 \\
& a. Tidak tersedia & 103 & 41,6 \\
\hline & b. Tersedia & & \\
\hline & &
\end{tabular}

$\begin{array}{lll}\text { tidak } & 9,914\end{array}$

\begin{tabular}{lllllllll} 
tersedia & 88 & 76,5 & 27 & 23,5 & 115 & 100 & 0,001 & $5,273-$ \\
\hline & 24 & 24,7 & 73 & 75,3 & 97 & 100 & &
\end{tabular}

$\begin{array}{lllllll}\text { Total } & 112 & 52,8 & 100 & 47,2 & 212 & 100\end{array}$

$\begin{array}{llllllll}\text { Aktif } & 81 & 71,7 & 32 & 28,3 & 113 & 100 & 0.001\end{array}$

0,015

wilayah kerja Puskesmas Kerumutan

Kabupaten Pelalawan. Untuk lebih jelasnya

Pembahasan

dapat dilihat pada analisis univariat dan

1. Analisis Univariat

bivariat berikut ini :

a. Bidan

Dari hasil penelitian bahwa untuk melihat keberadaan bidan, maka bidan dikelompokkan menjadi dua yaitu 
ketersediaan bidan dan tidak tersedianya bidan. Hasil penelitian menunjukkan bahwa sebagian besar responden mengatakan tidak tersedianya bidan di desa siaga yaitu sebanyak 115 orang $(54,2 \%)$. Hal ini tidak sesuai dengan kebijakan yang dianjurkan oleh kementerian kesehatan bahwa peran tenaga kesehatan dalam mewujudkan desa siaga sangat penting, dapat dilakukan melalui pemberdayaan masyarakat dengan cara menggalang kemitraan dengan masyarakat, melibatkan peran aktif masyarakat dalam mengatasi berbagai permasalahan yang dihadapi dengan mempertimbangkan potensi masyarakat serta sumber-sumber yang tersedia di masyarakat (Depkes RI, 2007).

\section{b. Kader}

Dari hasil penelitian bahwa untuk melihat keaktifan kader, maka kader dikelompokkan menjadi dua yaitu kader yang aktif dan tidak aktif. Hasil penelitian menunjukkan bahwa sebagian besar responden mengatakan kader tidak aktif yaitu sebanyak 113 orang $(53,3 \%)$. Hal ini merupakan implikasi dari tidak tersedianya bidan yang bertugas di suatu desa siaga, sehingga peran kader dalam melaksanakan tugasnya tidak terlaksana. Peran kader tergantung keaktifan bidan dalam memberdayakannya pada suatu kegiatan tertentu. Misalnya kegiatan Posyandu, kader akan menunjukkan kinerjanya jika program Posyandu diselenggarakan sesuai dengan waktu yang ditentukan.

Menurut Pemerintah Dalam Negri No.7 tahun 2007 tentang kader pemberdayaan masyarakat adalah anggota masyarakat Desa/Kelurahan yang memiliki pengetahuan dan kemauan untuk menggerakkan masyarakat berpartisipasi dalam pemberdayaan masyarakat dan pemanfaatan hasil pembangunan di desanya. Pemilihan Pengurus dan kader Desa siaga dilakukan melalui pertemuan khusus para pimpinan formal desa dan tokoh masyarakat serta beberapa wakil masyarakat. Pemilihan dilakukan secara musyawarah dan mufakat, sesuai dengan tata cara dan kriteria yang berlaku, dengan difasilitasi oleh Puskesmas (Depkes RI, 2007).

\section{c. Sarana Prasarana}

Dari hasil penelitian bahwa untuk melihat sarana dan prasarana dikelompokkan menjadi dua yaitu ketersediaan sarana prasarana dan tidak tersedianya sarana prasarana. Hasil penelitian menunjukkan bahwa sebagian besar responden mengatakan tidak tersedianya sarana prasarana di desa siaga yaitu sebanyak 109 orang $(51,4 \%)$. Hal ini membuktikan bahwa, kebutuhan transportasi untuk meningkatkan derajat kesehatan masih sangat dbutuhkan oleh masyarakat terutama bagi masyarakat terpencil. Kendala yang terjadi, dan sering dikeluhkan oleh masyarakat adalah jangkauan yang sulit menuju desa siaga. 
Salah satu sarana prasarana yang dibutuhkan untuk desa siaga adalah transuportasi yaitu ambulans desa. Ambulan desa adalah suatu alat tranportasi yang dapat digunakan untuk mengatar warga yang membutuhkan pertolongan dan perawatan di tempat pelayanan kesehatan. Ambulan desa dapat berupa alat-alat tranportasi yang dimiliki warga desa tersebut seperti becak, gerobak, andong, perahu, motor, mobil, dll. Peran kader disini memotivasi warga agar apabila suatu saat ada warga yang membutuhkan pertolongan untuk pergi ketempat pelayanan kesehatan dengan segera, dapat menggunakan alat transportasi yang dimilikinya sebagai ambulan Desa (Depkes RI, 2007).

\section{Analisis Bivariat}

a. Hubungan Faktor Bidan dengan Perkembangan Desa Siaga.

Hubungan faktor bidan dengan perkembangan desa siaga pada penelitian ini terdapat hubungan yang signifikan. Terlihat pada pada tabel 4.6 dapat diketahui bahwa $\mathrm{P}$ Value yang diperoleh adalah 0,001 , nilai ini menunjukkan bahwa P Value 0,001 < Alpha 0,05. Jadi dapat disimpulkan ada hubungan yang bermakna antara faktor bidan dengan perkembangan desa siaga. Hasil penelitian ini di dukuung oleh penelitian yang dilakukan Endang (2009), tentang analisis pengembangan desa siaga di Kabupaten Konawe Selatan Provinsi Sulawesi Tengah bahwa faktor dominan yang mempengaruhi perkembangan Desa Siaga adalah faktor petugas kesehatan yaitu bidan $(p=0,002)$. Begitu pula penelitian yang dilakukan oleh Susilawati (2010), tentang hubungan peran bidan terhadap perkembangan Desa Siaga di Kabupaten Banyumas bahwa adanya hubungan faktor peran petugas terhadap perkembangan desa siaga $(p=0,003)$. Peran tenaga kesehatan dalam mewujudkan desa siaga sangat penting, dapat dilakukan melalui pemberdayaan masyarakat dengan cara menggalang kemitraan dengan masyarakat, melibatkan peran aktif masyarakat dalam mengatasi berbagai permasalahan yang dihadapi dengan mempertimbangkan potensi masyarakat serta sumber-sumber yang tersedia di masyarakat (Depkes RI, 2007).

Berdasarkan hal di atas peneliti bersumsi bahwa penyelenggaran pengembangan desa siaga belum didukung dengan tersedianya sumber daya kesehatan yang memiliki kompetensi dalam mewujudkan masyarakat yang mampu dan tanggap terhadap masalahmasalah kesehatan yang terjadi di tengahtengah masyarakat. Apalagi peran tenaga kesehatan yang ada masih berorientasi upaya kuratif. Padahal tujuan yang ingin dicapai adalah upaya promotif dan preventif termasuk juga upaya pemberdayaan masyarakat. Selain itu, ketentuan untuk memenuhi minimal satu bidan dan dua kader dalam kebijakan pengembangan Desa Siaga 
ditetapkan karena terdapat keterbatasan sumber daya yang tidak memungkinkan menempatkan satu tim untuk setiap Desa Siaga. Ketentuan tersebut tidak mempertimbangkan kemampuan dan langkah-langkah untuk pemenuhan sumber daya secara nasional

b. Hubungan Faktor Kader dengan Perkembangan Desa Siaga

Hubungan faktor kader dengan perkembangan desa siaga pada penelitian ini terdapat hubungan yang signifikan. Terlihat pada pada tabel 4.4 dapat diketaui bahwa $\mathrm{P}$ Value yang diperoleh adalah 0.001 , nilai ini menunjukkan bahwa P Value $0.001<$ Alpha 0.05 . Jadi dapat disimpulkan ada hubungan yang bermakna antara faktor kader dengan perkembangan desa siaga. Salah satu kunci keberhasilan dan kelestarian Desa Siaga adalah keaktifan para kader (Depkes, 2009). Oleh karena itu, dalam rangka pembinaan perlu dikembangkan upaya untuk memenuhi kebutuhan pada kader agar tidak drop-out, kader-kader yang memiliki motivasi memuaskan kebutuhan sosial sikologisnya harus diberi kesempatan seluasnya untuk mengembangkan kreativitasnya. Sedangkan kader yang masih dibebani dengan pemenuhan kebutuhan dasarnya, harus dibantu untuk memperoleh pendapatan tambahan, misalnya dengan pemberian gaji/insentif atau fasilitas agar dapat berwirausaha. Dalam proses pemberdayaan inilah diperlukan peran pendamping untuk mengarahkan sumberdaya apa saja yang dapat mendukung dalam pengembangan desa siaga. Berkaitan dengan keterlibatan fasilitator (pelaku pemberdayaan) dalam mengawal proses pemberdayaan terhadap warga masyarakat, Sumodiningrat (2010) menjelaskan bahwa, pemberdayaan tidak bersifat selamanya, melainkan sampai target masyarakat mampu mandiri, dan kemudian dilepas untuk mandiri, meskipun dari jauh tetap dipantau agar tidak jatuh lagi. Meskipun demikian dalam rangka menjaga kemandirian tersebut tetap dilakukan pemeliharaan semangat, kondisi, dan kemampuan secara terus menerus supaya tidak mengalami kemunduran. Hasil penelitian ini didukung oleh penelitian yang dilakuan oleh Endang (2009), tentang analisis pengembangan desa siaga di Kabupaten Konawe Selatan Provinsi Sulawesi Tengah bahwa faktor dominan yang mempengaruhi perkembangan Desa Siaga adalah faktor petugas kesehatan yaitu kader $(p=0,002)$. Berdasarkan uraian di atas peneliti berasumsi bahwa keaktifan dan kemandirian kader dalam melaksanakan upaya-upaya kesehatan, kebijakan pengembangan desa siaga sudah tepat, namun dampak dari kebijakan tersebut masih kurang dirasakan dikarenakan implementasi pengembangan desa siaga belum dilaksanakan dengan maksimal. Kurangnya koordinasi dari semua elemen yang ada di desa dan kurangnya kesadaran masyarakat 
untuk berpartisipasi melaksanakan program yang telah ditetapkan tersebut.

c. Hubungan Faktor Sarana Prasarana dengan Perkembangan Desa Siaga.

Hubungan faktor bidan dengan perkembangan desa siaga pada penelitian ini terdapat hubungan yang signifikan. Terlihat pada pada tabel 4.4 dapat diketaui bahwa $\mathrm{P}$ Value yang diperoleh adalah 0.001 , nilai ini menunjukkan bahwa P Value $0.001<$ Alpha 0.05. Jadi dapat disimpulkan ada hubungan yang bermakna antara faktor sarana prasarna dengan perkembangan desa siaga. Faktor sarana prasarana yang dimaksudkan di atas adalah ketersediaannya alat transportasi ambulans untuk keperluan rujukan dari berbagai masalah kesehatan yang terjadi di masyarakat. Salah satu sarana prasarana yang dibutuhkan untuk desa siaga adalah transuportasi yaitu ambulans desa. Ambulan desa adalah suatu alat tranportasi yang dapat digunakan untuk mengatar warga yang membutuhkan pertolongan dan perawatan di tempat pelayanan kesehatan. Ambulan desa dapat berupa alat-alat tranportasi yang dimiliki warga desa tersebut seperti becak, gerobak, andong, perahu, motor, mobil, dll. Peran kader disini memotivasi warga agar apabila suatu saat ada warga yang membutuhkan pertolongan untuk pergi ketempat pelayanan kesehatan dengan segera, dapat menggunakan alat transportasi yang dimilikinya sebagai ambulan Desa (Depkes RI, 2007).
Hasil penelitian ini didukung oleh penelitian yang dilakukan oleh Endang (2009), tentang analisis pengembangan desa siaga di Kabupaten Konawe Selatan Provinsi Sulawesi Tengah bahwa faktor dominan yang mempengaruhi pengembangan Desa Siaga adalah faktor sarana dan prasarana $(\mathrm{p}=0,003)$. Berdasarkan uraian di atas peneliti berasumsi bahwa masyarakat membutuhkan adanya transportasi seperti ambulans sebagai sarana pendukung untuk meningkatkan derajat kesehatan terutama dalam keadaan gawat darurat. Perlunya keberadaan ambulans di desa siaga untuk memberikan rasa aman dan nyaman bagi masyarakat dalam penanggulangan kejadiana kegawatdaruratan. Argumentasi masyarakat terhadap fungsi ambulans adalah dengan tersedianya kelengkapan alat pendukung di dalam ambulans mampu memantau kondisi kesehatan penderita untuk mendapatkan penanganan lanjutan.

\section{Kesimpulan}

Setelah dilakukan penelitian tentang faktorfaktor yang mempengaruhi perkembangan di wilayah kerja Puskesmas Kerumutan Kabupaten Pelalawan terhadap 212 responden, maka dapat disimpulkan sebagai berikut:

1. Terdapat hubungan yang signifikan antara faktor bidan dengan perkembangan desa siaga di wilayah kerja Puskesmas Kerumutan 
Kabupaten Pelalawan ( $\mathrm{p}$ value $=$ $0.001<\alpha 0.05)$.

2. Terdapat hubungan yang signifikan antara faktor kader dengan perkembangan desa siaga di wilayah kerja Puskesmas Kerumutan Kabupaten Pelalawan ( $\mathrm{p}$ value $=$ $0.001<\alpha 0.05)$.

3. Terdapat hubungan yang signifikan antara faktor sarana prasarana dengan perkembangan desa siaga di wilayah kerja Puskesmas Kerumutan Kabupaten Pelalawan ( $p$ value $=$ $0.001<\alpha 0.05)$.

\section{Saran}

Disarankan bagi masyarakat dapat meningkatkan kesadarannya dalam meningkatakan derajat kesehatan melalui pembinaan oleh bidan desa dan kader kesehatan yang sudah terlatih. Peran serta masyarakat dalam pengembangan desa siaga juga memberikan kontribusi dalam mewujudkan derajat kesehatan yang optimal. Begitupun Puskesmas Kerumutan dan Desa Siaga untuk meningkatkan kerjasama untuk berkolaborasi dalam pencapaian keberhasilan program desa siaga.

\section{Daftar Pustaka}

Adisasmito, W. (2007). Sistem Kesehatan. Jakarta: Raja Grafindo Persanda.

Azwar, A. (1996). Pengantar Administrasi Kesehatan Edisi Ketiga. Jakarta: Binarupa Aksara.
Balaka. (2010). Tinjauan Pelaksanaan Pembangunan Kesehatan Masyarakat Desa di Kecamatan Linea Kabupaten Onnes. PSKM MRS FKM UI.

Depkes RI. (2002). ARRIME Pedoman Manajemen Puskesmas. Jakarta: Departemen Kesehatan RI.

Depkes RI. (2003). Kebijakan Dasar Puskesmas (menuju indonesia sehat). Jakarta: Departemen Kesehatan RI.

Depkes RI. (2006). Pedoman Pelaksanaan Pengembangan Desa Siaga. Jakarta: Departemen Kesehatan RI

Depkes RI. (2006). Petunjuk Teknis Penggerakan dan Pemberdayaan Masyarakat dalam Pengembangan Desa Siaga. Jakarta: Departemen Kesehatan RI

Endang, S.(2009). Analsis Kesiapan Pengembangan Desa Siaga di Kabupaten Konawe Selatan Provinsi Sulawesi Tengah Tahun 2009. PSKM MRS FKM UI.

Hartono, B. (2010). Promosi Kesehatan di Puskesmas \& Rumah Sakit. Jakarta: Rineka Cipta.

Kamal, N. (2007). Analisis Isi Berita Buletin Pengembangan Desa Siaga di Provinsi Jawa Barat Edisi Perdana Bulan Maret 2007 Produksi Seksi Promosi Kesehatan Dinas Kesehatan Provinsi Jawa Barat. PSKM MRS FKM UI.

Kementerian Kesehatan. (2010). Rencana Stategis Kementerian Kesehatan RI 20102014. Jakarta: Kementerian Kesehatan RI.

Kementerian Kesehatan. (2010). Pusat Promosi Kesehatan Pedoman Umum Pengembangan Desa dan Kelurahan Siaga Aktif. Jakarta: Kementrian Kesehatan RI.

LindaS, R. (2008).Analisis Keberlangsungan Upaya Pemberdayaan Masyarakat Dalam Pelaksanaan Desa Siaga Kabupaten Subang Tahun 2008. PSKM MRS FKM UI.

Muninjaya,G.(2004). Manajemen Kesehatan. Jakarta: Penerbit buku kedokteran EGC.

Notoatmodjo, S.(2005). Promosi Kesehatan Teori dan Aplikasi. Jakarta: Rieneka Cipta Notoatmodjo,S.(2005). Metodologi Penelitian Kesehatan. Jakarta : PT. Rineka Cipta. Notoatmodjo, S.(2007). Kesehatan Masyarakat Ilmu \& Seni. Jakarta: Rieneka Cipta. 
Sopacua, D.(2009). Riview Kebijakan pada Indikator Pengembangan Desa Siaga di Provinsi Jawa Timur, Manajemen Pelayanan Kesehatan, Volume 12/Desember/2009, (No. 04). Pusat Manajemen Pelayanan Kesehatan Fakultas Kedokteran Universitas Gadjah Mada.

Satori, D.(2009). Metodologi Penelitian Kualitatif. Bandung: ALFABETA, cv.

Yustin, P.(2011). Analisis Kesiapan Poskesdes Dalam Pengembangan Desa Siaga di Kecamatan Tikal Kabupaten Toraja. PSKM MRS FKM UI. 